\title{
FAKTOR YANG BERHUBUNGAN DENGAN KECEMASAN IBU DALAM MENGHADAPI PERSALINAN SECTIO CAESAREA DI RSIA SITTI KHADIJAH I MAKASSAR
}

\author{
Lola Novianti ${ }^{1}$, Rusni Mato ${ }^{2}$, Hasifah ${ }^{3}$ \\ ${ }^{1}$ STIKES Nani Hasanuddin Makassar \\ ${ }^{2}$ Poltekkes kesehatan makassar \\ ${ }^{3}$ STIKES Nani Hasanuddin Makassar \\ Alamat Korespondensi: (wardhalf@yahoo.com / 082349312138)

\begin{abstract}
ABSTRAK
Kecemasan adalah perasaan yang efektif tidak menyenangkan disertai dengan sensasi fisik yang memperingati orang-orang terhadap bahaya yang akan datang. Keadaan yang tidak menyenangkan seringkali kabur dan sulit ditunjukkan dengan tepat, tetapi kecemasan itu sendiri selalu terasa. Tujuan dari penelitian ini adalah untuk mengetahui faktor-faktor yang berhubungan dengan kecemasan ibu dalam menghadapi seksio sesarea di RSIA Sitti Khadijah I Makassar. Penelitian ini menggunakan metode analitik asosiatif dengan pendekatan cross sectional yang diadakan 26 Desember-Jan. 26. Populasi dalam penelitian ini adalah semua ibu hamil yang akan menjalani persalinan Caesar di RSIA Sitti Khadijah I Makassar. Metode pengambilan sampel yang digunakan adalah accidental sampling dan jumlah sampelnya 62 pasien. Hasil penelitian ini menunjukkan pengetahuan $(p=0,032)$, dukungan keluarga $(p=0,036)$, dan komunikasi terapeutik $(p=0,022)$ dengan kecemasan pada ibu dalam menghadapi persalinan sectio caesarea. Kesimpulan penelitian ini adalah ada hubungan pengetahuan, dukungan keluarga, dan komunikasi terapeutik dengan kecemasan pada ibu dalam menghadapi persalinan sectio caesarea di RSIA Sitti Khadijah I Makassar. Diharapkan dapat menambah pengetahuan ibu hamil tentang persalinan sectio caesarea untuk mengurangi kecemasan ibu sebelum menjalani persalinan.
\end{abstract}

Kata kunci: Kecemasan Pada Ibu, Dukungan Keluarga, Pengetahuan Dan Komunikasi Terapi

\section{PENDAHULUAN}

Section caesarea adalah suatu tindakan untuk pelahiran janin lewat insisi menembus dinding abdomen dan uterus.

Menurut World Health Organization (WHO), rata-rata SC $5-15 \%$ per 1000 kelahiran di dunia, angka kejadian di rumah sakit pemerintah rata-rata $11 \%$ sementara di rumah sakit swasta bisa lebih dari $30 \%$ permintaan SC di sejumlah Negara berkembang melonjak pesat setiap tahunnya. Selain itu, menurut WHO prevalensi SC meningkat $46 \%$ di Cina dan $25 \%$ di Asia , Eropa, dan Amerika Latin. Hal ini didukung oleh Corso, et al (2017) yang menyatakan bahwa SC menjadi salah satu kejadian dengan prevalensi yang meningkat di dunia (Surmayati, Widodo, \& Puraningsih, 2018).

$\mathrm{Di}$ Indonesia sendiri, angka kejadian operasi sesar juga terus meningkat baik di Rumah Sakit Pemerintah maupun Rumah Sakit Swasta Menurut Kemenkes RI angka kejadian sectio Caesarea dari 34 provinsi pada tahun 2016 sebanyak 5.111.204 menunjukkan kelahiran dengan metode operasi sesar (Hardhana, Yudianto, \& Soenardi, 2017). Sedangkan pada tahun 2017 angka kejadian Sectio Caesarea dari 34 provinsi sebanyak 5.320 .550 kasus (Kurniawan, Hardhana, \& Yudianto, 2018).

Data untuk wilayah Provinsi Sulawesi Selatan, yang telah tercatat di Dinas Kesehatan Kota Makassar pada tahun 2016, angka kejadian sectio Caesarea yaitu, 323.629 kasus (Hardhana, Yudiano, \& Soenardi, 2017).

Berdasarkan data dari rekam medik Rumah Sakit Ibu dan Anak Sitti Khadijah 1 Makassar, pada tahun 2016 tercatat pasien kasus sectio caesarea 2.432 kasus, pada tahun 2017 tercatat pasien kasus sectio caesarea 2.562 kasus, sedangkan pada tahun 2018 mulai bulan januari sampai bulan September tercatat pasien kasus section caesarea 1725 kasus.

\section{BAHAN DAN METODE}

Lokasi, populasi, sampel

Jenis penelitian ini merupakan penelitian kuantitatif dengan metode analitik asosiatif, yaitu penelitian yang bertujuan untuk mengetahui hubungan antara dua variabel atau lebih serta mengetahui pengaruhnya dengan menggunakan rancangan 'cross 
sectional'. Penelitian dilaksanakan di Rumah Sakit Ibu dan Anak Sitti Khadijah I Makassar pada tanggal 26 Desember s/d 26 Januari 2019. Populasi pada penelitian ini berjumlah 168 , dan sampel berjumlah 62 .

1. Kriteria Inklusi
a. Ibu yang akan dilakukan persalinan Sectio Caesarea di RSIA Sitti Khadijah I Makassar.
b. Dalam kondisi sadar
c. Dapat berkomunikasi dengan baik
d. Bersedia untuk menjadi responden

2. Kriteria Eksklusi
a. Ibu yang pada saat peneliti berlangsung menolak untuk melanjutkan jadi responden.
b. Tidak mengisi secara lengkap lembar informed consent dan data-data yang diperlukan
c. Tidak kooperatif
d. Ibu yang memiliki komplikasi persalinan.

\section{Pengumpulan Data}

1. Data Primer

Dalam penelitian ini, seluruh data diambil secara langsung dari responden (data primer), yang meliputi data faktor yang berhubungan dengan tingkat kecemasan ibu dalam menhadapi persalinan Sectio Caesarea di RSIA Sitti Khadijah I Makassar, data diukur menggunakan alat kuesioner. Data mobilisasi dini dan pemulihan luka diukur menggunakan alat ukur kuesioner dengan skala guttman.

2. Data Sekunder

Data yang diperoleh dari rekam medik di RSIA Sitti Khadijah I Makassar.

Pengolahan Data

1. Editing (Penyuntingan)

Editing adalah upaya untuk memeriksa kembali kebenaran data yang diperoleh atau dikumpulkan. Editing dapat dilakukan pada tahap pengumpulan data atau setelah data terkumpul.

2. Coding (Pengkodean)

Coding merupakan kegiatan pemberian kode numerik (angka) terhadap data yang terdiri atas beberapa kategori.

3. Data Entry / Tabulation (Tabulating)

Data entry adalah kegiatan memasukkan data yang telah dikumpulkan ke dalam master tabel atau database komputer, komudian membuat distribusi frekuensi sederhana atau bisa juga dengan membuat tabel kontengensi.

4. Teknik Analisis / Analisa Data

Dalam melakukan analisis, khususnya terhadap data penelitian akan menggunakan ilmu statistik terapanyang disesuaikan dengan tujuan yang hendak dianalisis.

\section{Analisa data}

1. Analisis Univariat

Teknik ini dilakukan terhadap setiap variabel hasil dari penelitian. Hasil dari analisis ini berupa distribusi frekuensi, dengan melihat presentasi masing-masing variabel penelitian. analisis univariat ini digunakan untuk mengetahui proporsi dan masing-masing variabel penelitian.

2. Analisis Bivariat

Merupakan model analisis untuk mengetahui interaksi dua variabel, baik berupa komparatif, asosiatiff, maupun korelatiff dengan menggunakan uji wilcoxon.

\section{HASIL}

1. Analisis Univariat

Tabel 1 Distribusi Karakteristik Responden Di Wilayah Kerja Puskesmas Tamalanrea Kota Makassar Tahun $2018(n=42)$

\begin{tabular}{|c|c|c|}
\hline Karakteristik & $\mathrm{n}$ & $\%$ \\
\hline Umur & & \\
18--25 & 10 & 16,1 \\
31-30 & 36 & 58,1 \\
\hline Pekerjaan & 16 & 25,8 \\
IRT & 41 & 66,1 \\
PNS & 5 & 8,1 \\
Pegawai swasta & 6 & 9,7 \\
Wiraswasta & 10 & 16,1 \\
\hline Pendidikan & & \\
SD & 3 & 4,8 \\
SMP & 5 & 8,1 \\
SMA & 35 & 56,5 \\
S1 & 19 & 30,6 \\
\hline Pengetahuan & & \\
Baik & 26 & 41,9 \\
Kurang & 36 & 58,1 \\
\hline
\end{tabular}

dari 42 responden, yang frekuensi terbanyak pada umur Ibu 17-25 tahun yaitu sebanyak 22 responden $(52,4 \%)$, dan frekuensi terendah 36-45 tahun sebanyak 2 responden (4,8\%).frekuensi pekerjaan terbanyak ada pada IRT dengan jumlah frekuesi sebanyak 28 responden $(66,7 \%)$, dan pada pekerjaan yang terendah jumlah frekuensinya ada pada wiraswasta yaitu sebanyak 5 responden (11,9\%).pendidikan terakhir terbanyak ada pada tingkat SMA dengan jumlah frekuesi sebanyak 15 responden $(35,7 \%)$, dan pada pendidikan terakhir yang terendah jumlah frekuensinya ada pada tingkat Perguruan tinggi yaitu sebanyak 4 responden (9,5\%). responden 
yang memiliki umur anak dengan jumlah frekuensi terbanyak ada pada umur 9 bulan dengan jumlah frekuensi 25 responden $(59,5 \%)$ dan umur anak dengan jumlah frekuensi terendah ada pada umur 10 bulan dengan jumlah frekuensi 4 responden (9,5\%).frekuensi terbanyak pada jumlah anak yaitu sebanyak 15 responden $(35,2 \%)$, dan frekuensi terendah yaitu 5 responden $(4,8 \%)$.

2. Analisis Bivariat

Tabel 2 Pengaruh Motivasi, Pengetahuan dan Budaya Ibu terhadap pemberian Imunisasi Campak Di Wilayah Kera Puskesmas Tamalanre Kota Makassar.

\begin{tabular}{|c|c|c|c|c|c|c|}
\hline \multirow{3}{*}{$\begin{array}{l}\text { Penget } \\
\text { ahuan }\end{array}$} & \multicolumn{4}{|c|}{ Tingkat Kecemasan } & \multirow{2}{*}{\multicolumn{2}{|c|}{ total }} \\
\hline & \multicolumn{2}{|c|}{$\begin{array}{l}\text { Tidak } \\
\text { cemas }\end{array}$} & \multicolumn{2}{|c|}{ Cemas } & & \\
\hline & $\mathrm{n}$ & $\%$ & $\mathrm{n}$ & $\%$ & $\mathrm{n}$ & $\%$ \\
\hline Baik & 16 & 25,8 & 10 & 16,1 & 26 & 100 \\
\hline Kurang & 8 & 12,9 & 28 & 45,2 & 36 & 100 \\
\hline Total & 24 & 38,7 & 38 & 61,3 & 62 & 100 \\
\hline
\end{tabular}

Berdasarkan tabel 2 menunjukkan bahwa hasil uji statistic dengan Chi-square diperoleh nilai $p=0,01$. Karena nilai $p<\alpha=$ 0,002 , maka hipotesis nol ditolak dan hipotesis nol ditolak dan hipotesis alternative diterima. Interpretasi ada hubungan pengetahuan dengan kecemasan pada ibu hamil dalam menghadapi persalinan Sectio Caesarea.

\begin{tabular}{|c|c|c|c|c|c|c|}
\hline \multirow{2}{*}{$\begin{array}{c}\text { Duku } \\
\text { ngan } \\
\text { Keluarga }\end{array}$} & \multicolumn{2}{|c|}{$\begin{array}{c}\text { Tingkat Kecemasan } \\
\text { Tidak } \\
\text { cemas }\end{array}$} & \multicolumn{2}{|c|}{ Cemas } & \multicolumn{2}{|c|}{ total } \\
\cline { 2 - 7 } & $\mathrm{n}$ & $\%$ & $\mathrm{n}$ & $\%$ & $\mathrm{n}$ & $\%$ \\
\hline Baik & 14 & 22,6 & 7 & 11,3 & 21 & 100 \\
\hline Kurang & 10 & 16,1 & 31 & 50,0 & 41 & 100 \\
\hline Total & 24 & 38,7 & 38 & 61,3 & 62 & 100 \\
\hline
\end{tabular}

Uji Satistik Chi-square : $(\alpha)=0,05 \quad p=0,067$

Berdasarkan tabel 2 menunjukkan bahwa hasil uji statistik dengan Chi-square diperoleh nilai $p=0,001$. Karena nilai $p<\alpha$ $=0,01$, maka hipotesis nol ditolak dan hipotesis alternatif diterima. Interpretasi ada hubungan dukungan keluarga dengan kecemasan pada Ibu dalam menghadapi nproses persalinan.

\begin{tabular}{|c|c|c|c|c|c|c|}
\hline $\begin{array}{c}\text { Komu } \\
\text { nikasi } \\
\text { terape } \\
\text { utik }\end{array}$ & \multicolumn{2}{|c|}{$\begin{array}{c}\text { Tingkat Kecemasan } \\
\text { cemas }\end{array}$} & \multicolumn{2}{|c|}{ Cemas } & \multicolumn{2}{|c|}{ total } \\
\cline { 2 - 7 } & $\mathrm{n}$ & $\%$ & $\mathrm{n}$ & $\%$ & $\mathrm{n}$ & $\%$ \\
\hline Baik & 15 & 24,2 & 10 & 16,1 & 30 & 100 \\
\hline Kurang & 9 & 14,5 & 28 & 45,2 & 32 & 100 \\
\hline Total & 24 & 38,7 & 38 & 61,3 & 62 & 100 \\
\hline Uji Satistik Chi-square: $(\alpha)=0,05 p=0,005$ \\
\hline
\end{tabular}

Berdasarkan tabel 2 menunjukkan Hasil uji statistic dengan Chi-square diperoleh nilai $p=0,005$. Karena nilai $p<\alpha=$ 0,01 maka hipotesis nol ditolak dan hipotesis alternatif diterima. Interpretasi ada hubungan komunikasi terapeutik perawat dengan kecemasan pada ibu dalam menghadapi persalinan Sectio Caesarea.

\section{PEMBAHASAN}

1. Hubungan motivasi ibu dengan pemberian imunisasi campak

Berdasarkan tabel 2 diatas menggambarkan bahwa dari 19 ibu responden yang memiliki motivasi tinggi, terdapat 13 responden $(31,0 \%)$ yang memiliki sikap yang baik terhadap imunisasi campak, dan 6 responden $(14,3 \%)$ yang memiliki sikap kurang baik, bahwa ibu yang memiliki motivasi tinggi menunjukkan sikap baik yang tinggi. Motivasi seseorang dapat ditimbulkan dan tumbuh berkembang melalui dirinya sendiri-intrinsik dan dari lingkunganekstrinsik. Sedangkan dari 23 ibu responden yang memiliki motivasi rendah, terdapat 5 responden $(11,9 \%)$ yang memiliki sikap baik terhadap imunisasi campak, dan 18 responden (42,9\%) yang memiliki sikap kurang baik, bahwa ibu yang memiliki motivasi rendah menunjukkan sikap kurang baik. Motivasi ekstrinsik yang menjadi penyebab tidak diberikannya imunisasi pada bayi seperti desas-desus yang didengar oleh ibu tentang imunisasi seperti, adanya anggapan yang menyatakan bahwa imunisasi tersebut tidak berguna, imunisasi menyebabkan anak sakit, imunisasi tersebut haram untuk diberikan pada bayi dan seterusnya.

Berbanding terbalik dengan penelitian Triana (2016), hasil analisis statistik pada variabel motivasi memperoleh nilai $p$-value sebesar 0,000 ( $p$ value < 0,05 ), berarti adanya hubungan yang bermakna antara motivasi orang tua dengan pemberian imunisasi dasar lengkap pada bayi, dimana di dalamnya terdapat imunisasi campak, Artinya Orang tua yang memiliki motivasi rendah terhadap imunisasi berisiko 2,88 kali lebih besar tidak memberikan imunisasi campak pada bayinya dari pada ibu yang memiliki motivasi cukup.

Motivasi seseorang dapat ditimbulkan dan tumbuh berkembang melalui dirinya sendiri-intrinsik dan dari lingkungan-ekstrinsik. Motivasi ekstrinsik menjadi salah satu penyebab tidak 
dilakukannya imunisasi pada bayi karena desas-desus yang didengar oleh ibu tentang imunisasi seperti, adanya anggapan yang menyatakan bahwa imunisasi tersebut tidak berguna, imunisasi menyebabkan anak sakit, imunisasi tersebut haram untuk diberikan pada bayi dan seterusnya (Triana, 2016).

2. Hubungan pengetahuan ibu dengan pemberian imunisasi campak

Dari hasil penelitian tabel 2 diatas menggambarkan bahwa dari 20 ibu responden yang memiliki pengetahuan cukup, terdapat 12 responden (28,6\%) yang memiliki sikap yang baik terhadap imunisasi campak, dimungkinkan ibu yang berpengetahuan baik mengetahui pentingnya imunisasi campak pada bayi dan 8 responden $(19,0 \%)$ yang memiliki sikap kurang baik, dimungkinkan karena anggapan ibu tentang imunisasi campak akan memberikan efek samping seperti, demam tinggi, dan berpotensi timbul kelainan. Sedangkan dari 22 ibu responden yang memiliki pengetahuan kurang, terdapat 6 responden $(14,3 \%)$ yang memiliki sikap baik terhadap pemberian imunisasi campak, diduga informasi yang ibu dapatkan melalui puskesmas dan kader tentang pentingnya imunisasi campak pada bayi. Dan 16 responden $(38,1 \%)$ yang memiliki sikap pemberian imunisasi kurang baik, dimungkinkan karena ibu tidak mengeahui pentingnya imunisasi campak dan terpengaruh oleh informasi tentang efek samping yang berbahaya setelah di imunisasi.

Sejalan dengan penelitian yang dilakukan oleh Nurani (2013) di desa Truko Kecamatan Kangkung Kabupaten Kendal, bahwa hasil uji fisher's exact menunjukkan tidak ada hubungan antara pengetahuan ibu dengan kelengkapan imunisasi dasar dimana nilai $p$ value $=1,000$ lebih besar dari nilai a 0,05 maka $\mathrm{Ha}$ ditolak dan $\mathrm{Ho}$ diterima.

Sejalan pula dengan penelitian yang dilakukan oleh Rati Anggraeni Puspita (2015) di Desa Pal IX Kecamatan Sungai Kakap Kabupaten Kubu Raya. Dari hasil rekapitulasi analisis bivariat dengan menggunakan uji Chi-Square bahwa tidak ada hubungan antara pengetahuan ( $p=$ 0,509 ) dengan kelengkapan imunisasi dasar.

Tidak sejalan dengan penelitian Astuti \& Hartini (2017), menunjukkan hasil analisis statistik uji Chi Square diketahui bahwa nilai $p$ value $=0,001$ yaitu lebih kecil dari tingkat kemaknaan $\alpha<0,05$ maka $\mathrm{Ho}$ ditolak dan $\mathrm{Ha}$ diterima. Hal ini menunjukkan bahwa ada hubungan antara pengetahuan dengan tingkat kejadian campak.

3. Hubungan budaya ibu dengan pemberian imunisasi campak

Berdasarkan Tabel 2 menunjukkan bahwa dari 26 ibu responden yang memiliki budaya kuat, terdapat 6 responden (14,3\%) yang memiliki sikap yang baik terhadap imunisasi campak, dan 20 responden $(47,6 \%)$ yang memiliki sikap kurang baik, bahwa ibu yang memiliki budaya kuat menunjukkan sikap kurang baik. Diduga responden mempercayai bahwa imunisasi membawa dampak buruk terhadap bayi atau balita mereka, seperti panas, kejang, dan rewel. Sedangkan dari 16 ibu responden yang memiliki budaya lemah, terdapat 12 responden $(28,6 \%)$ yang memiliki sikap baik terhadap imunisasi campak, dan 4 responden $(9,5 \%)$ yang memiliki sikap pemberian imunisasi kurang baik. Bahwa ibu yang memiliki budaya lemah menunjukkan sikap baik, dikarenakan tradisi dikeluarga tidak terbiasa memberikan imunisasi, namun dengan tingkat pendidikan yang tinggi dan pengetahuan yang baik dapat merubah seseorang menjadi lebih baik dari sebelumnya.

Peneliti ini didukung dengan penelitian yang dilakukan oleh Rahmawati (2014) dari hasil uji statistik diperoleh nilai $p$ $0,000(p<\alpha)$ yang berarti ada hubungan antara tradisi keluarga terhadap kelengkapan imunisasi pada bayi atau balita. OR $=75,250$ artinya tradisi keluarga yang tidak terbiasa memberikan imunisasi beresiko 8,700 kali menyebabkan ketidaklengkapan imunisasi dasar pada bayi atau balita dibandingkan tradisi keluarga yang terbiasa memberikan imunisasi pada bayi atau balita mereka.

Budaya dapat tetap bertahan karena adanya beberapa unsur. Budaya mempunyai fungsi dan terjaring luas dalam masyarakat. Unsur budaya diperoleh dari proses sosialisasi sejak kecil oleh masingmasing individu. Unsur kebudayaan dapat mencakup agama dan religi yang dianut masyarakat. Selain itu, budaya juga menyangkut ideology dan falsafah hidup bangsa (Sunaryo, 2015)

\section{KESIMPULAN}

1. Tidak ada pengaruh motivasi terhadap sikap ibu dalam pemberian imunisasi campak 
2. Tidak ada pengaruh pengetahuan terhadap sikap ibu dalam pemberian imunisasi campak

3. Ada pengaruh budaya terhadap sikap ibu dalam pemberian imunisasi campak

\section{SARAN}

1. Diharapkan Petugas pelaksana imunisasi terkhususnya puskesmas perlu secara rutin melakukan kegiatan tentang pentingnya imunisasi untuk tumbuh kembang anak, terutama kepada ibu-ibu yang memiliki bayi dan lebih meningkatkan kerja sama dengan jajaran pemerintah desa dan kader kesehatan untuk bersama-sama berperan aktif dalam menyebarkan informasi

\section{DAFTAR PUSTAKA}

Lestari, A. B., Sitaresmi, M. N., \& Wibowo, T. (2017). Ketepatan Waktu Vaksinasi Campak Sebagai Faktor Preventif Kejadian Campak Di Kota Yogyakarta. Berita Kedokteran Masyarakat (BKM) Journal of Community Medicine and Public Health, 249-254.

Hidayat, A. A. (2017). Metodologi Penellitian Keperawatan dan Kesehatan. Jakarta: Salemba Medika.

Nursalam. (2016). Metodologi Penelitian Ilmu Keperawatan. Jakarta: Salemba Medika.

Triana, V. (2016). fakor yang berhubungan dengan pemberian imunisasi dasar lengkap pada bayi tahun 2015. artikel penelitian.

Astuti, D., \& Hartini, S. (2017). Hubungan Pengetahuan dan Status Imunisasi dengan Tingkat Kejadian Campak Di Wilayah Puskesmas Kayen Kabupaten Pati. PROSDING HEFA (Health Event For All).

Sunaryo. (2015). Sosiologi Untuk Keperawatan. Jakarta: Bumi Medika. 